\title{
Rain Attenuation Estimation with the Numerical Weather Prediction Model WRF: Impact of Rain Drop Size Distribution for a Temperate Climate
}

\author{
Laurent Quibus ${ }^{1}$, Valentin Le Mire ${ }^{1}$, Julien Queyrel ${ }^{1}$, Laurent Castanet ${ }^{1}$, Laurent Féral ${ }^{2}$ \\ ${ }^{1}$ (ONERA): ONERA/DEMR, Université de Toulouse, France, Laurent.Quibus@ onera.fr \\ ${ }^{2}$ (LA): Laboratoire d'Aérologie, Université de Toulouse, France, Laurent.Feral@aero.obs-mip.fr
}

\begin{abstract}
Frequencies at and above $\mathrm{K} / \mathrm{Ka}$ band are required for the deployment of (very) high throughput satellites. Yet, radio-links at those frequencies are strongly affected by tropospheric constituents, especially rain. The knowledge of the signal attenuation due to rain comes from dedicated propagation experiments with satellite beacons. Numerical Weather Prediction models could act as an alternative source of rain information, but the validation of their performances against beacon data remains incomplete, notably with respect to the local climatology. This work takes a look at the rain attenuation predicted with the Weather Research and Forecasting (WRF) model 4.0.3 initialized with ERA-5 data, tests nine microphysics schemes, either single- or double-moment, and adapts rigorously the electromagnetic model to their assumed rain drop size distributions. Results are compared over three months in Toulouse, in a temperate region, at both 20.2 and $39.4 \mathrm{GHz}$, and a strategy is outlined to select the best parametrizations from the error metrics.
\end{abstract}

Index Terms - drop size distribution, Numerical Weather Prediction, propagation measurements, rain attenuation, temperate climate, tropospheric propagation.

\section{INTRODUCTION}

Satellite communication systems and related applications must exploit electromagnetic waves at increasingly higher frequencies to meet the expectations regarding data rates and volumes. More and more systems appear in the $20-50 \mathrm{GHz}$ range (K, Ka, Q, V bands), and others could use 70-80 GHz (W band) [1], [2]. At those frequencies, the systems benefit from smaller components, better gains and directivities. However, the carrier waves get more heavily affected by their interactions with the troposphere as they propagate through it. In particular, the attenuation of the transmitted power during rain events can no longer be compensated by fixed margins. Fade Mitigation Techniques (FMTs) [3], such as smart gateway switching, must be developed in order to maintain the system availability, especially for feeder links at $\mathrm{Q} / \mathrm{V}$ band. The successful design of FMTs requires references for the quantification of tropospheric effects at high frequencies, with first and foremost the attenuation due to rain.

The characterization of the rain attenuation on space-toEarth radio-links is primarily conducted thanks to ground stations measuring narrowband beacon signals emitted from a geosynchronous satellite. A current example is the Alphasat campaign (19.7 and $39.4 \mathrm{GHz}$ ) [4]. Running these propagation experiments presents high costs and is a long-term endeavor as, in order to collect a statistically representative picture for rain, multiple years of measurements are needed [5], [6]. Therefore, a method to simulate rain attenuation from more widely available data would be a great asset to palliate the limited experimental coverage in locations and in frequency.

Numerical Weather Prediction (NWP) models at high spatial and temporal resolutions (a few kilometers and a few minutes) are attractive tools for the reproduction of close-to real atmospheric conditions in order to model the rain attenuation on an Earth-space path anywhere in the world. Simulators of propagation impairments exploiting NWP runs were described in [7], [8] and in [9], [10]. The aforementioned works showed there are generally poor instantaneous correlations between NWP rain attenuation estimates and beacon measurements (maybe 10-30 \%), but very encouraging agreements were found between their Complementary Cumulative Distribution Functions (CCDFs) over periods varying from a few months to a year (with errors of about 1-5 dB). Notably good statistical agreements were reported at $20.2 \mathrm{GHz}$ in the south of France for small scale diversity sites over a one-year period [11]. Other studies have shown promises for the applications of NWP forecasts directly to FMTs [12], [13], or similarly for space missions [14], [15]. A more thorough statistical validation of the NWP performances would however still benefit any design based on them. In particular, the selection of NWP parametrizations should be assessed to correspond to the climatic specificities, not only in temperate regions, but also for equatorial and tropical regions where fewer measurements exist [16], to capture seasonal/monthly variations.

This paper investigates the role the water microphysics, and hence also the rain drop size distribution, plays on the rain attenuation CCDFs. In that regard, Mie scattering is applied to correspond rigorously to the assumptions in the NWP output. This work is carried out over Toulouse, in a temperate zone, but where long-term beacon measurements are available concurrently at two frequencies (20.2 and $39.4 \mathrm{GHz})$ [17], [18], and for which site diversity measurements $(20.2 \mathrm{GHz})$ [19] also exist. Both aspects are useful to ascertain the representativeness of the results. The work is first reported here for a test period of three months, and for nine microphysics schemes.

Sec. II describes the methodology further, the set-up, NWP configurations, and the electromagnetic model. Sec. III presents and discusses the results. Sec. IV ends the paper. 


\section{METHODOLOGY}

This section exposes the reference dataset, the parameters of the simulations and the modelling approach.

\section{A. Geographical Setting And Reference Data}

The ground station of Toulouse $\left(43.57^{\circ} \mathrm{N}, 1.47^{\circ} \mathrm{E}\right)$ is located in the southwest of France, and it has a mid-latitude temperate climate with oceanic influences. The station measures the signals from ASTRA-3B at $20.2 \mathrm{GHz}$ (Ka band) and Alphasat at $39.4 \mathrm{GHz}$ (Q band) with elevations of about $35^{\circ}$. The beacon receivers have been operational since April 2011 and June 2015 respectively, and measurements are on-going. Within this work, the dataset of interest is the excess attenuation. The details of the processing methods used to extract the excess attenuation are in [17], [18]. At these frequencies and for time percentages lower than $1 \%$ of an average year, the main contributor to the excess attenuation is the rain attenuation. Concurrent radiometric measurements allows to flag rain events accurately, whereas scintillation fade and enhancement mostly balance out statistically at such a high elevation [20].

A period of three months is selected to serve as basis for this work: February, May, and November 2016.

\section{B. NWP Configurations}

The NWP model in use is the Weather Research and Forecasting (WRF) model 4.0.3 with its Advanced Research WRF (ARW) core [21]. The initial and boundary conditions are taken from ERA-5 pressure and surface level data $\left(1 \mathrm{~h}, 0.25^{\circ}\right)$.

For the simulations, two nested 100 by 100 Lambert conformal conic domains with horizontal resolution of $6 \mathrm{~km}(\mathrm{~d} 01)$ and $2 \mathrm{~km}$ (d02) are built (see Fig. 1) around Toulouse. The outer domain contains the Pyrenees, the Massif Central, and a part of the Iberian System; the Bay of Biscay is in the northwest and the Mediterranean Sea in the southeast; it has also the river basins of the Ebro and the Garonne, the latter which makes up most of the inner domain used for the modelling.

The common parameters of the WRF simulations are inspired by previous results with the models [5], [16]:

- 37 levels of the vertical coordinate.

- Hydrostatic solver for d01 (6 km), and non-hydrostatic solver for $\mathrm{d} 02(2 \mathrm{~km})$.

- $\quad$ Fixed time steps of $36 \mathrm{~s} \mathrm{(d01)} \mathrm{and} 12 \mathrm{~s}$ (d02).

- No cumulus scheme (convection is assumed to be resolved at both resolutions of $6 \mathrm{~km}$ and $2 \mathrm{~km}$ ).

- $\quad$ RRTMG scheme for long- and short-wave radiations, called every $6 \mathrm{~min}(\mathrm{~d} 01)$ and $1 \mathrm{~min}(\mathrm{~d} 02)$.

- 5-layer thermal diffusion in land-surface interactions.

- MM5 and YSU schemes for surface layer and planetary boundary layer (PBL), called every $5 \mathrm{~min}$.

- $\quad$ Rayleigh implicit gravity-wave damping layer (0.2/s).

- Spectral analysis nudging activated (above 10th vertical level with default coefficients).

Nine microphysics parametrizations are tested in total:

- Single-moment: WSM6, Lin, Eta, Goddard.

- Double-moment: WDM6, Thompson, MilbrandtYau, Morrison, NSSL 2-moment.

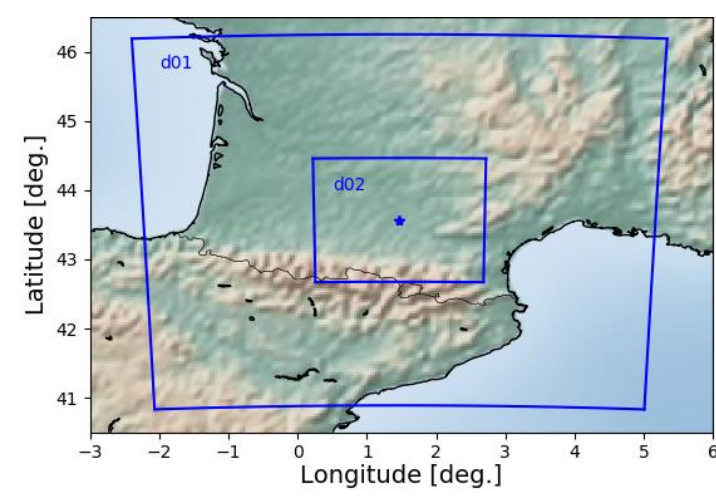

Fig. 1. WRF $(100,100) 6 \mathrm{~km}$ and $2 \mathrm{~km}$ domains around Toulouse

\section{Electromagnetic Model}

The general approach to convert the output of a NWP model into propagation variables is given by [9]. The rain attenuation $A_{R}(\mathrm{~dB})$ at the frequency $f(\mathrm{GHz})$ is a path integral of the specific rain attenuation $\gamma_{R}(\mathrm{~dB} / \mathrm{km})$ expressed as

$$
\gamma_{R}(f, T)=\gamma_{R, 0} \int_{0}^{\infty} \sigma_{\text {ext }}(f, T, D) n_{R}(D) d D
$$

with $\sigma_{\text {ext }}\left(\mathrm{m}^{2}\right)$ the extinction cross section, $n_{R}$ the rain drop size distribution $\left(\mathrm{m}^{-1} \mathrm{~m}^{-3}\right), T(\mathrm{~K})$ the air temperature, $D$ the drop diameter $(\mathrm{m})$, and $\gamma_{R, 0}=4.343 \times 10^{3} \mathrm{~dB} \cdot \mathrm{m} / \mathrm{km}$.

The rain drop size distribution $n_{R}$ is often assumed to be a gamma distribution with parameters $\mu$ and $\Lambda\left(\mathrm{m}^{-1}\right)$ as in

$$
\begin{aligned}
n_{R}(D) & =N_{R} \frac{\Lambda^{\mu+1}}{\Gamma(\mu+1)} D^{\mu} \exp (-\Lambda D) \\
& =N_{R, 0} D^{\mu} \exp (-\Lambda D)
\end{aligned}
$$

with $N_{R}\left(\mathrm{~m}^{-3}\right)$ the number density of drops or $N_{R, 0}\left(\mathrm{~m}^{-\left(3+\mu_{R}\right)}\right)$ the $D=0$ intercept. An exponential distribution is obtained from (2) when $\mu=0$. The Marshall-Palmer distribution is a well-supported average rain DSD in a temperate climate and it is an exponential DSD for which $N_{R, 0}=8 \times 10^{6} \mathrm{~m}^{-1} \mathrm{~m}^{-3}$.

Here the following DSDs are assumed: Marshall-Palmer for single-moment, exponential for double-moment except for WDM6 $(\mu=1)$. Single-moment schemes only output the rain mass mixing ratio $q_{R}(\mathrm{~kg} / \mathrm{kg})$, when double-moment schemes also yield $N_{R}$. How to recover $\Lambda$ from the distribution's moments is explored in greater generality in [22].

\section{CCDFs And Error Metrics}

From time series of the rain attenuation $A_{R}$, either experimental or simulated from WRF, its Complementary Cumulative Distribution Function (CCDF) is described by its graph $\left(P\left(A_{R}>A_{R}^{*}\right), A_{R}^{*}\right)$. Due to the experimental dynamic range, $A_{R}$ is capped at $30 \mathrm{~dB}$ in all results. Taking the experimental CCDF (ECCDF) as reference, the Root-Mean Square Error (RMSE) of the simulated CCDF is given in the probability range $0.1 \%$ to $10 \%$, and conditioned further to values of the ECCDF exceeding $0.25 \mathrm{~dB}$ at $20.2 \mathrm{GHz}$ or $1 \mathrm{~dB}$ at $39.4 \mathrm{GHz}$ to limit the analysis to rain (i.e. excluding contributions from clouds). The same is applied to the ITU testing variable [23]. 
TABLE I. PERFORMANCE METRICS OF RAIN ATTENUATION ESTIMATES FOR FEBRUARY 2016 IN TOULOUSE

\begin{tabular}{|c|c|c|c|c|}
\hline \multirow{2}{*}{$\begin{array}{c}\text { WRF micro- } \\
\text { physics }\end{array}$} & \multicolumn{2}{|c|}{$\begin{array}{c}\text { RMSE [dB] } \\
(\mathbf{0 . 1}-\mathbf{1 0} \%)\end{array}$} & \multicolumn{2}{c|}{$\begin{array}{c}\text { ITU RMSE [/] } \\
(\mathbf{0 . 1}-\mathbf{1 0} \%)\end{array}$} \\
\cline { 2 - 5 } & $\mathbf{2 0 . 2 ~ G H z}$ & $\mathbf{3 9 . 4} \mathbf{~ G H z}$ & $\mathbf{2 0 . 2} \mathbf{~ G H z}$ & $\mathbf{3 9 . 4} \mathbf{~ G H z}$ \\
\hline WSM6 & $0.71(\# 4)$ & $1.48(\# 3)$ & $0.40(\# 2)$ & $0.27(\# 3)$ \\
\hline Lin & $0.42(\# 1)$ & $0.72(\# 1)$ & $0.29(\# 1)$ & $0.14(\# 1)$ \\
\hline Eta & $0.85(\# 6)$ & $1.90(\# 6)$ & $0.51(\# 8)$ & $0.38(\# 6)$ \\
\hline Goddard & $0.92(\# 8)$ & $2.24(\# 7)$ & $0.50(\# 6)$ & $0.40(\# 7)$ \\
\hline WDM6 & $0.68(\# 3)$ & $0.97(\# 2)$ & $0.42(\# 4)$ & $0.25(\# 2)$ \\
\hline Thompson & $0.82(\# 5)$ & $1.69(\# 5)$ & $0.46(\# 5)$ & $0.30(\# 5)$ \\
\hline M.-Yau & $0.96(\# 9)$ & $2.69(\# 9)$ & $0.57(\# 9)$ & $0.53(\# 8)$ \\
\hline Morrison & $0.67(\# 2)$ & $1.64(\# 4)$ & $0.33(\# 2)$ & $0.27(\# 3)$ \\
\hline NSSL & $0.86(\# 7)$ & $2.59(\# 8)$ & $0.50(\# 6)$ & $0.53(\# 8)$ \\
\hline
\end{tabular}

TABLE II. PERFORMANCE METRICS OF RAIN ATtENUATION ESTIMATES FOR MAY 2016 IN TOULOUSE

\begin{tabular}{|c|c|c|c|c|}
\hline \multirow[t]{2}{*}{$\begin{array}{l}\text { WRF micro- } \\
\text { physics }\end{array}$} & \multicolumn{2}{|c|}{$\begin{array}{l}\text { RMSE [dB] } \\
(0.1-10 \%)\end{array}$} & \multicolumn{2}{|c|}{$\begin{array}{c}\text { ITU RMSE [/] } \\
(0.1-10 \%) \\
\end{array}$} \\
\hline & $20.2 \mathrm{GHz}$ & 39.4 GHz & $20.2 \mathrm{GHz}$ & $39.4 \mathrm{GHz}$ \\
\hline WSM6 & 2.07 (\#8) & $6.14(\# 7)$ & $0.31(\# 7)$ & $0.35(\# 6)$ \\
\hline Lin & 0.92 (\#5) & 3.89 (\#6) & $0.15(\# 2)$ & $0.27(\# 4)$ \\
\hline Eta & $0.65(\# 3)$ & $3.14(\# 5)$ & $0.15(\# 2)$ & $0.29(\# 5)$ \\
\hline Goddard & $2.54(\# 9)$ & $7.95(\# 9)$ & 0.38 (\#9) & $0.50(\# 9)$ \\
\hline WDM6 & $1.91(\# 7)$ & $7.22(\# 8)$ & $0.29(\# 6)$ & $0.45(\# 8)$ \\
\hline Thompson & 0.93 (\#6) & $2.00(\# 2)$ & $0.26(\# 5)$ & $0.17(\# 2)$ \\
\hline M.-Yau & $0.76(\# 4)$ & $3.01(\# 4)$ & $0.31(\# 7)$ & $0.36(\# 7)$ \\
\hline Morrison & $0.59(\# 2)$ & $2.03(\# 3)$ & $0.15(\# 2)$ & $0.17(\# 2)$ \\
\hline NSSL & $0.22(\# 1)$ & $0.49(\# 1)$ & $0.07(\# 1)$ & $0.06(\# 1)$ \\
\hline
\end{tabular}

TABle III. Performance Metrics Of RAin AtTEnUATION ESTIMATES FOR NOVEMBER 2016 IN TOULOUSE

\begin{tabular}{|c|c|c|c|c|}
\hline \multirow[t]{2}{*}{$\begin{array}{l}\text { WRF micro- } \\
\text { physics }\end{array}$} & \multicolumn{2}{|c|}{$\begin{array}{l}\text { RMSE [dB] } \\
(0.1-10 \%) \\
\end{array}$} & \multicolumn{2}{|c|}{$\begin{array}{c}\text { ITU RMSE [/] } \\
(0.1-10 \%) \\
\end{array}$} \\
\hline & $20.2 \mathrm{GHz}$ & 39.4 GHz & $20.2 \mathrm{GHz}$ & $39.4 \mathrm{GHz}$ \\
\hline WSM6 & $0.24(\# 2)$ & $1.08(\# 2)$ & $0.08(\# 1)$ & $0.17(\# 2)$ \\
\hline Lin & $0.34(\# 3)$ & $0.81(\# 1)$ & $0.12(\# 3)$ & $0.14(\# 1)$ \\
\hline Eta & 0.49 (\#5) & $3.60(\# 9)$ & 0.15 (\#4) & $0.33(\# 9)$ \\
\hline Goddard & $0.13(\# 1)$ & $1.64(\# 5)$ & $0.08(\# 1)$ & $0.18(\# 3)$ \\
\hline WDM6 & $0.34(\# 3)$ & $2.21(\# 8)$ & 0.15 (\#4) & $0.20(\# 6)$ \\
\hline Thompson & $0.98(\# 9)$ & $1.79(\# 7)$ & $0.45(\# 9)$ & $0.28(\# 8)$ \\
\hline M.-Yau & $0.74(\# 8)$ & $1.72(\# 6)$ & $0.30(\# 8)$ & $0.26(\# 7)$ \\
\hline Morrison & $0.71(\# 7)$ & $1.28(\# 3)$ & $0.26(\# 7)$ & $0.18(\# 3)$ \\
\hline NSSL & $0.68(\# 6)$ & $1.37(\# 4)$ & $0.25(\# 6)$ & 0.19 (\#5) \\
\hline
\end{tabular}

\section{RESULTS AND DISCUSSION}

This section shows the comparison of the CCDFs and error metrics month by month and as a whole.

\section{A. February 2016}

The CCDFs for February 2016 are shown in Fig. 2 and the details of the RMSE metrics, along with a ranking of the parametrisations, are in Table I (using degraded colors from lowest errors in bright green to highest ones in bright red).

The rain attenuation in February, a winter month associated with stratiform rain events, is rather low, reaching only a bit more than $2.5 \mathrm{~dB}$ and $8 \mathrm{~dB}$ for $0.1 \%$ of the time respectively at $20.2 \mathrm{GHz}$ and $39.4 \mathrm{GHz}$. All the WRF-based CCDFs

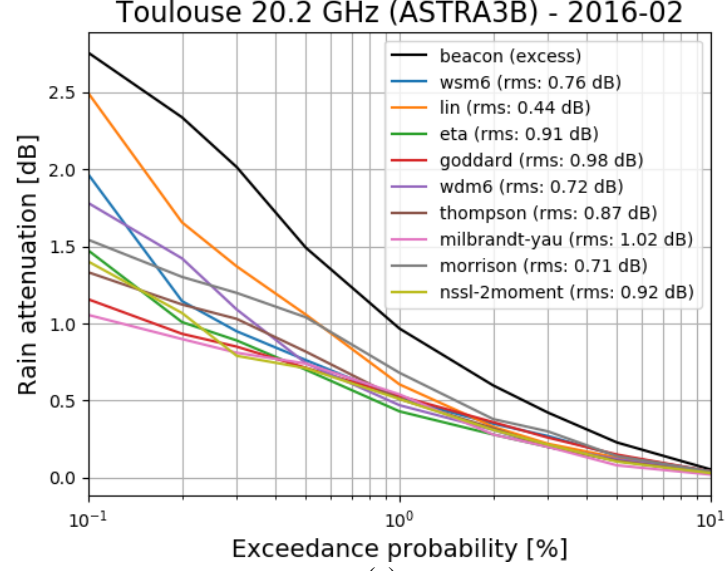

(a)

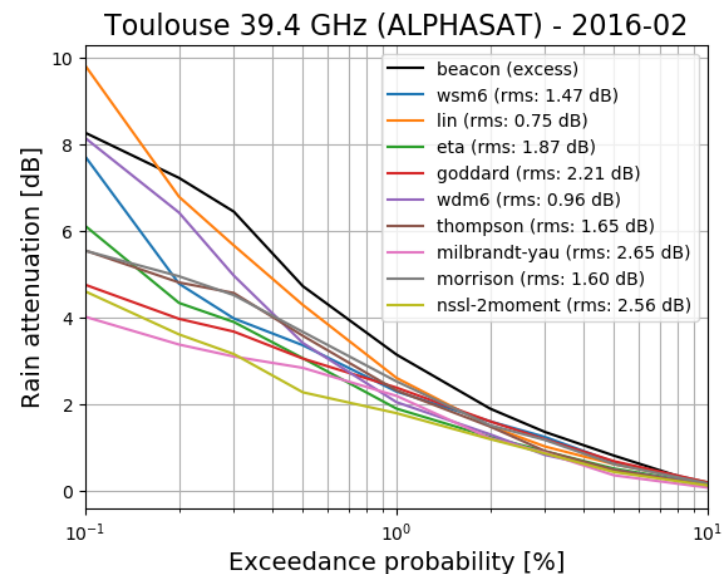

(b)

Fig. 2. Rain attenuation CCDFs for Toulouse at $20.2 \mathrm{GHz}$ (a) and 39.4 $\mathrm{GHz}$ (b) in February 2016, comparison of measurements with WRF

are below the ECCDF most of the time. The results with the Lin scheme are generally seen to be the closest to the ECCDF. This is confirmed by the error metrics as Lin gets the best rank for all of them. Next in line are the related WSM6 and WDM6 parametrizations performing similarly, and the Morrison scheme doing roughly as well. Then, the Thompson parametrization ranks fifth consistently for all metrics. The other parametrizations result in too low attenuation levels in relation to the ECCDF. Goddard, Eta, and NSSL all give poor results, with the Milbrandt-Yau scheme having the overall worst ones.

\section{B. May 2016}

The CCDFs for May 2016 are shown in Fig. 3 and the associated error metrics are in Table II.

The rain attenuation in May, a spring month with rather convective events, is high, especially compared to February, and especially at $39.4 \mathrm{GHz}$ where for $0.1 \%$ of the time the ECCDF reaches $20 \mathrm{~dB}$ and some parametrizations even cap at $30 \mathrm{~dB}$. There are under- or overestimation of the ECCDF depending on the chosen parametrization, with a trend towards overestimation. This goes in the opposite direction from the situation in February, illustrating that discrepancies in behaviors can appear with monthly considerations. 


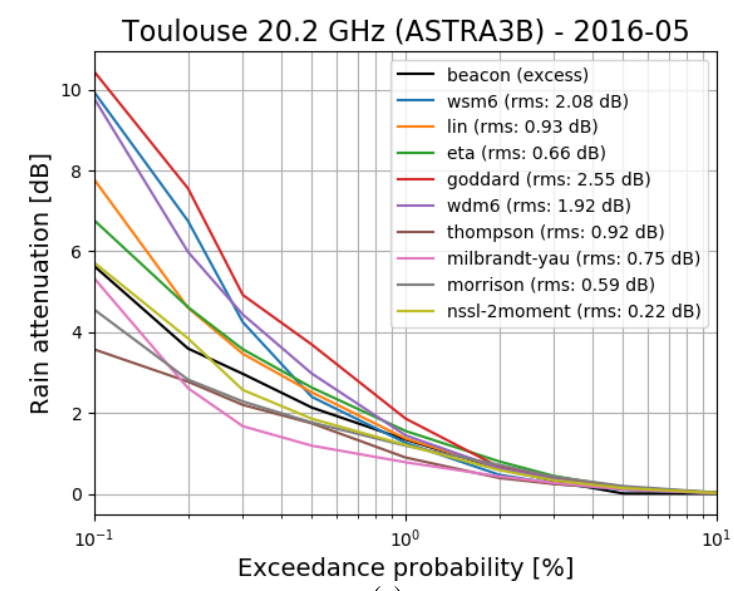

(a)

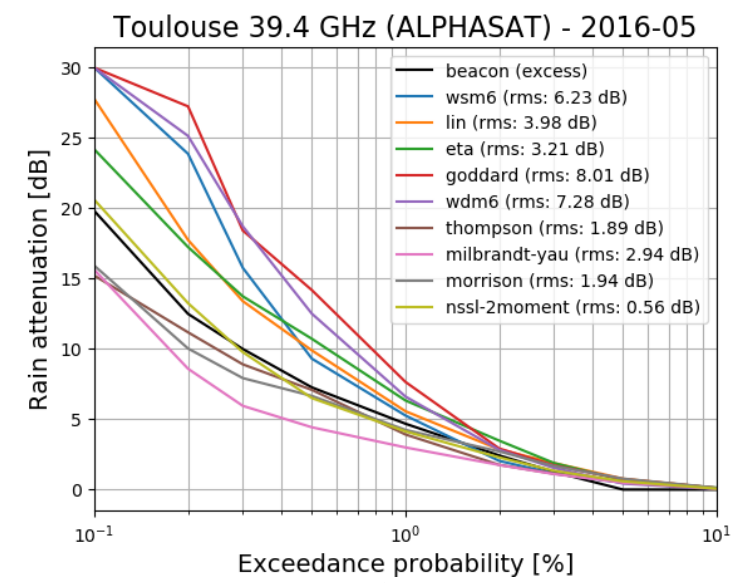

(b)

Fig. 3. Rain attenuation CCDFs for Toulouse at $20.2 \mathrm{GHz}$ (a) and 39.4 $\mathrm{GHz}$ (b) in May 2016, comparison of measurements with WRF

As February, May has a clear winner in terms of estimation of the ECCDF. Indeed, the NSSL scheme produces CCDFs very close (distance $<1 \mathrm{~dB}$ ) to the ECCDF at both frequencies, and tops the performance rankings, with RMSEs of only $0.2 \mathrm{~dB}$ and $0.5 \mathrm{~dB}$ at $20.2 \mathrm{GHz}$ and $39.4 \mathrm{GHz}$ respectively. The second best performer is arguably the Morrison scheme, though it underestimates the ECCDF noticeably at lower probabilities of exceedance, particularly at $39.4 \mathrm{GHz}$ where it only has the third best RMSE. After that, it gets harder to point out a strict order for the other parametrizations, with several ones claiming second and third spots (tied or not) for a metric. Differences in performances between Ka and Q band are more flagrant than in February, likely due to the higher attenuation and possibly accentuated by the limit in dynamic range. Still decent results are obtained by Lin and Eta schemes, though overestimating the ECCDF by a few $\mathrm{dB}$ at $39.4 \mathrm{GHz}$, and the Thompson scheme which is similar to Morrison at $39.4 \mathrm{GHz}$ but underestimates the ECCDF too much at 20.2 GHz. WSM6, WSDM6, and Goddard get a bad ranking as they too strongly overestimate the ECCDF. The performances of Milbrandt-Yau are also poor, especially at Q band, once again due to the underestimation of the ECCDF.

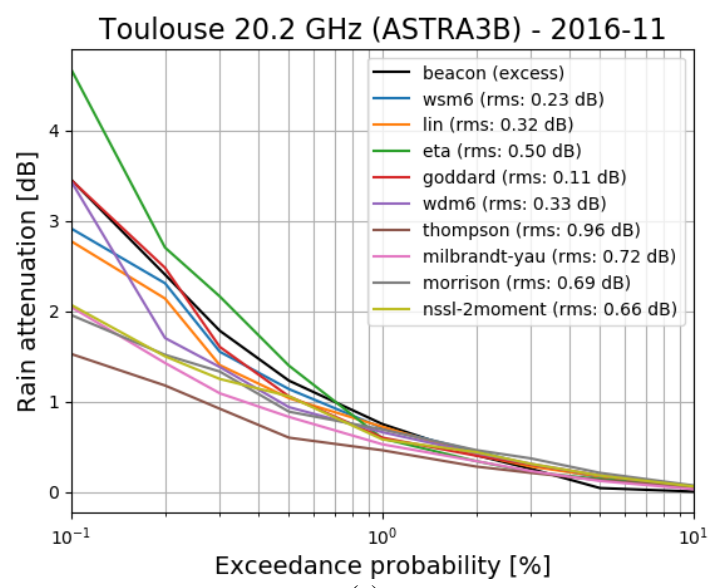

(a)

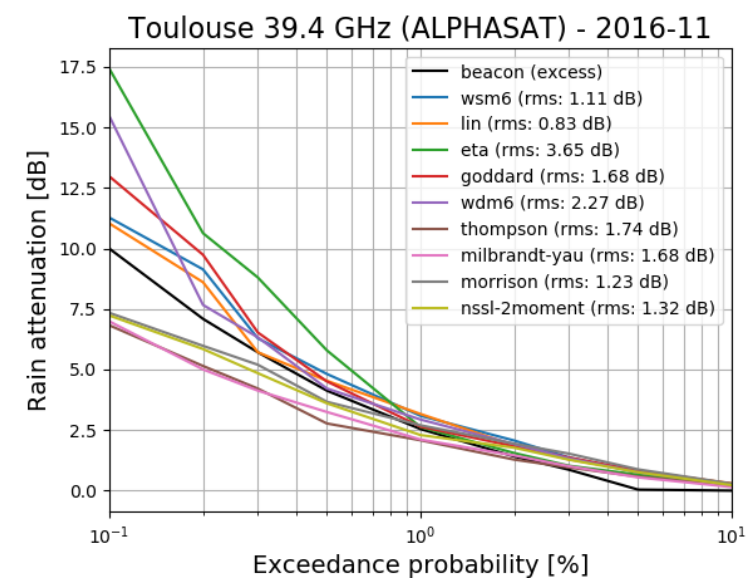

(b)

Fig. 4. Rain attenuation CCDFs for Toulouse at $20.2 \mathrm{GHz}$ (a) and 39.4 $\mathrm{GHz}$ (b) in November 2016, comparison of measurements with WRF

\section{November 2016}

The CCDFs for November are shown in Fig. 4 and the associated error metrics are in Table III.

The rain attenuation in November, an autumn month, is slightly higher than in February but much lower than in May. For $0.1 \%$ of the time, the ECCDF stands at $3.5 \mathrm{~dB}$ and $10 \mathrm{~dB}$ at $20.2 \mathrm{GHz}$ and $39.4 \mathrm{GHz}$ respectively. As in May, certain WRF schemes either under- or overestimate the ECCDF, with mostly underestimations at $20.2 \mathrm{GHz}$ but a more even spread of the curves above and below the reference at $39.4 \mathrm{GHz}$.

The best performance is obtained by WSM6, with Lin not far behind, with the former performing better at $20.2 \mathrm{GHz}$ and the latter better at $39.4 \mathrm{GHz}$, as their simulated CCDFs shift from under- to overestimating the ECCDF. Goddard also gets rather good results, and ranks first at $20.2 \mathrm{GHz}$. WDM6 is not too far from WSM6 at $20.2 \mathrm{GHz}$ but gets a poorer score at $39.4 \mathrm{GHz}$ as its overestimation is more pronounced. Morrison and NSSL have mediocre performances as they underestimate the ECCDF, which penalizes them at Ka band. Milbrandt-Yau and Thompson underestimations are even worse. Eta gets a terrible rank at $39.4 \mathrm{GHz}$ as it reaches $17.5 \mathrm{~dB}$ for $0.1 \%$ of the time (against $10 \mathrm{~dB}$ for the ECCDF). 


\section{Common Observations}

In spite of the variations in the performances of the schemes over that short test period of three months, some candidates appear more promising than others. Among singlemoment schemes, Lin performs altogether well, WSM6 does well except in May, Eta and Goddard get generally poorer results. Among double-moment schemes, NSSL gets remarkable results in May but overestimates the other ECCDFs, WDM6 has a similar but usually worst performance than WSM6, while Morrison and Thompson rather underestimate the ECCDFs, and Milbrandt-Yau does it even more so.

The inconsistencies observed in the performances for a given scheme from month to month tend also to show there is a point in looking at different microphysics on a seasonal basis. Moreover, the behavior of the NWP results at the two frequencies demonstrates on the one hand that acceptable performances are possible at both, and on the other hand that it is useful to have more than one frequency for validation.

\section{CONCLUSION}

The contribution reports an evaluation over three months of a rain attenuation model based on WRF 4 and ERA-5 initialization data. Reference beacon data is available at two frequencies $(20.2 \mathrm{GHz}$ and $39.4 \mathrm{GHz}$ ) for Toulouse (temperate climate). A rigorous approach accounting for microphysics schemes underlying rain drop size distribution identifies promising candidates (Lin, WSM6, NSSL) and shows the need to account for seasonal and monthly differences.

Further validation is needed, for a longer period of time, using beacon data from other sites (including diversity sites and in other climates). ONERA current and planned measurements will be exploited in order to contribute to that objective.

\section{REFERENCES}

[1] R. De Gaudenzi, P. Angeletti, D. Petrolati and E. Re, "Future technologies for very high throughput satellite systems," International Journal of Satellite Communications and Networking, vol. 38, no. 2, 2019, pp. 141-161.

[2] L. Luini, R. Nebuloni and C. Riva, "Ka-to-W Band EM wave propagation: tropospheric effects and countermeasures," Wave Propagation Concepts for Near-Future Telecommunication Systems, IntechOpen, 2017.

[3] A.D. Panagopoulos, "Propagation phenomena and modeling fo fixed satellite systems: evaluation of fade mitigation techniques," Radio wave propagation and channel modeling for Earth-space systems, CRC Press, 2017.

[4] C. Riva and A. Martellucci, "Preface to the special issue on the Alphasat Aldo Paraboni propagation experiment," International Journal of Satellite Communications and Networking, vol. 37, no. 5, 2019, pp. 385-386.

[5] N. Jeannin, X. Boulanger, L. Féral, L. Castanet and F. Lacoste, "Interannual variability, risk and confidence intervals associated with propagation statistics. Part I: theory of estimation," International Journal of Satellite Communications and Networking, vol. 32, no. 5, pp. 407-421.

[6] X. Boulanger, N. Jeannin, L. Féral, L. Castanet, F. Lacoste and F. Carvalho, "Inter-annual variability, risk and confidence intervals associated with propagation statistics. Part II: parameterization and applications," International Journal of Satellite Communications and Networking, vol. 32, no. 5, pp. 423-441.
[7] D.D. Hodges, R.J. Watson and G. Wyman, "An attenuation time series model for propagation forecasting," IEEE Transactions on Antennas and Propagation, vol. 54, no. 6, 2006, pp. 1726-1733.

[8] D.D. Hodges, R.J. Watson and G. Wyman, "Initial comparisons of forecast attenuation and beacon measurements at 20 and $40 \mathrm{GHz}$," 1st European Conference on Antennas and Propagation (EuCAP), Nice, France, 2006

[9] M. Outeiral García, N. Jeannin, L. Féral and L. Castanet, "Use of WRF model to characterize propagation effects in the troposphere," 7th European Conference on Antennas and Propagation (EuCAP), Gothenburg, Sweden, 2013

[10] N. Jeannin, et al., "Atmospheric Channel Simulator for the simulation of propagation impairements for $\mathrm{Ka}$ band data downlink," 8th European Conference on Antennas and Propagation (EuCAP), The Hague, The Netherlands, 2014

[11] G. Fayon, L. Féral, L. Castanet, N. Jeannin, and X. Boulanger, "Use of WRF to generate site diversity statistics in south of France," XXXIInd General Assembly and Scientific Symposium of the International Union of Radio Science (URSI GASS), Montréal, Canada, 2017.

[12] I. Dahman, P. Arbogast, N. Jeannin and B. Bennamar, "Rain attenuation prediction model for satellite communications based on the Météo-France ensemble prediction system PEARP," Natural Hazards and Earth System Sciences, vol. 18, no. 12, 2018, pp. 3327-3341.

[13] N. Jeannin, L. Castanet, I. Dahman, V. Pourret and B. Pouponneau, "Smart gateways switching control algorithms based on tropospheric propagation forecasts," International Journal of Satellite Communications and Networking, vol. 37, no. 1, 2019, pp. 43-55.

[14] M. Biscarini et al., "Optimizing data volume return for Ka-band deep space links exploiting short-term radiometeorological model forecast," IEEE Transactions on Antennas and Propagation, vol. 64, no. 1, 2016, pp. 235-250.

[15] M. Biscarini et al., "Satellite link-budget statistics prediction from weather forecast models: verification with Hayabusa-2 Ka-band data," 14th European Conference on Antennas and Propagation, 2020, Copenhagen, Denmark.

[16] V. Le Mire, X. Boulanger, L. Castanet, B. Bennamar and L. Féral, "Potentialities of the Numerical Weather Prediction model WRF to produce attenuation statistics in tropical regions," 14th European Conference on Antennas and Propagation (EuCAP), Copenhagen, Denmark, 2020.

[17] X. Boulanger, B. Gabard, L. Casadebaig and L. Castanet, "Four years of total attenuation statistics of Earth-space propagation experiments at Ka-Band in Toulouse," IEEE Transactions on Antennas and Propagation, vol. 63, no. 5, 2015, pp. 2203-2214.

[18] X. Boulanger and L. Castanet, "Ka and Q band propagation experiments in Toulouse using ASTRA 3B and ALPHASAT satellites," International Journal of Satellite Communications and Networking, vol. 37, no. 5, 2019, pp. 449-459.

[19] X. Boulanger, F. Lacoste and L. Castanet, "Small an large scale site diversity experiment at Ka-band in the south of France," International Journal of Satellite Communications and Networking, vol. 36, no. 1, 2018, pp. 14-28.

[20] M. Rytir, "Clear-air scintillation and multipath for low-elevation highlatitude satellite communication links," 9th European Conference on Antennas and Propagation (EuCAP), Lisbon, Portugal, 2015.

[21] W.C. Skamarock et al., "A description of the Advanced Research WRF model version 4," NCAR TN-566+STR, 2019.

[22] M. Thurai, V. Bringi, P.N. Gatlin, W.A. Petersen, M.T. Wingo, "Measurements and modelling of the full rain drop size distribution," Atmopshere, vol. 10, no. 1, 2019.

[23] ITU-R Study Group 3, "Working Party $3 \mathrm{M}$ fascicle on testing variables used for the selection of prediction methods (Rev. 1)," 2016. 